\title{
FACTORS INFLUENCING BROWN SKUA REPRODUCTIVE SUCCESS AT ELEPHANT ISLAND - ANTARCTICA
}

http://dx.doi.org/10.4322/apa.2014.031

\author{
Suzana Seibert ${ }^{1, *}$, Adriando Duarte $^{1}$, Maria Virginia Petry ${ }^{1}$
}

\author{
${ }^{1}$ Laboratório de Ornitologia e Animais Marinhos - LOAM, Universidade do Vale do Rio dos Sinos - UNISINOS, \\ São Leopoldo, Rio Grande do Sul, Brazil \\ *e-mail: suzanaseibert@gmail.com
}

\begin{abstract}
The objective of the present study is to evaluate how some variables could influence breeding successes of Brown Skua (Catharacta lonnbergi) at Stinker Point, Elephant Island, Antarctica. Variables measured were Intra-specific Nearest Neighbour Distance (NND), Penguin Colony Distance (PCD) and egg laying date per breeding pair. Variables that could influence Chick Survival Probability were analysed through logistic regression (forward). Data was collected during the 2009/10 austral summer. The studied population consisted of 37 breeding pairs, from which $23.7 \%(n=9)$ successfully raised chicks to fledging. NND and PCD significantly affected chick survival (Nagelkerke $R^{2}=0.21, p<0.001$ and Nagelkerke $R^{2}=0.54, p<0.05$, respectively), showing that chicks have lower survival probability among closer nests and among the nests that are near penguin colony. There is a positive and significant relation between NND and PCD (Linear $\left.R^{2}=0.38, p<0,001\right)$. There was no significant relationship between the chick survival and egg laying date. Analysis showed different tendencies from those presented in other studies where chick survival probability was lower in nests near the penguin colony and an early egg laying date did not reflect a higher chick survival probability as expected. The last one probably caused by severe weather during the beginning of the studied breeding season and many nests were covered by snow, which caused the loss of many eggs resulting in very low reproductive success.
\end{abstract}

Keywords: Catharacta lonnbergi, chick, near neighbour, spatial distribution

\section{Introduction}

Brown Skua (Catharacta lonnbergi) is a top-predator seabird, mainly found in the Southern Oceans and the Antarctic Continent (Watson, 1975). Reproductive success is one of the measures used to monitor bird populations. Finding out how many breeding pairs have successfully raised their chicks and knowing what factors can be determining for some specific population's reproductive success, offers information whether a population is growing, declining or stable and what forces can guide one or other condition. Researchers have suggested some factors influencing breeding success, such as distance from the nest to the nearest breeding penguin group (Pezzo et al., 2001), egg laying date (Phillips et al., 2004), hatching date (Hahn \&
Peter, 2003; Ritz et al., 2005) and adult quality (Phillips et al., 1998; Ritz et al., 2005). In some populations, Brown Skua individuals defend feeding territory in a penguin colony. Hagelin and Miller (1997) suggested that Skuas breeding near penguin colonies select their territories to be sufficiently close to penguin colonies to have accessible resources, but sufficiently far from penguin colonies to avoid egg and chick loss due to penguin deployments and to avoid other skua territories and intra-specific predation, but not evaluating if this habitat selection could influence breeding success. The number of near neighbours and the distances from them can play an important factor on 
chick body-condition, which influence breeding success (Phillips et al., 1998).

One biological characteristic that many studies show to be very important for reproductive success is egg laying date and hatching date. Breeding pairs that lay their eggs earlier have higher chick survival probability (Phillips et al., 2004), which is a common characteristic in bird reproductive ecology (Pezzo et al., 2001). The potential advantage of individuals occupying different nest locations within the colony and their individual biological characteristics can be studied by comparing the characteristics of successful and unsuccessful nests. The objective of the present study is to evaluate the effect of conspecific nearest neighbour distance, distance from breeding pairs to the nearest penguin colony and, egg laying date on breeding successes of Brown Skua population (Catharactalonnbergi) in Elephant Island, Antarctica.

\section{Materials and Methods}

The field work was carried out at Stinker Point (61 $11^{\circ}$ ' S and $55^{\circ} 22^{\prime} \mathrm{W}$ ), Elephant Island, South Shetland, Antarctic Peninsula during the 2009/10 austral summer. Brown Skua population consisted of 37 breeding pairs. Variables measured for each breeding pair were the mean of three conspecific Nearest Neighbour Distance (NND), Penguin Colony Distance (PCD) and egg laying date. To access the breeding success and egg laying date, the nests were visited every three days. Chicks were assumed to have fledged if they had survived until the end of the study period (age \pm 34 days). Nest positions were recorded with a handheld GPS receiver (60CSx, Garmim). The parameters NND and PCD were calculated by means of GIS software ArcView. Logistic regression (forward) was used in order to analyze the influence of variables over Chick Survival Probability.

\section{Results}

From the 37 Brown Skua breeding pairs 24.3\% (n = 9) successfully raised chicks to fledging, which meant 0.24 chick fledged per breeding pair. Mean Skua Nearest Neighbour Distance (NND) was $51 \pm 71 \mathrm{~m}$ (ranging from 3.1 to $407.3 \mathrm{~m}$ ). Variables influencing Chick Survival
Probability were NND (Nagelkerke $\mathrm{R}^{2}=0.52 ; \mathrm{P}<0.001$ ) and PCD (Nagelkerke $\left.\mathrm{R}^{2}=0.22 ; \mathrm{P}<0,01\right)$. Results indicate that the further nests are from each other, the higher is chick survival probability (Figure 1). The same tendency was confirmed for PCD. A positive relationship was found between NND and PCD (Linear $\mathrm{R}^{2}=0.38, \mathrm{P}<0,001$ ), where nests located near the penguin colony were densely distributed. There was no significant relationship of chick survival with egg laying date $(\mathrm{P}>0,05)$ (Figure 2$)$, which ranged between 13 December of 2009 and 5 January of 2010.

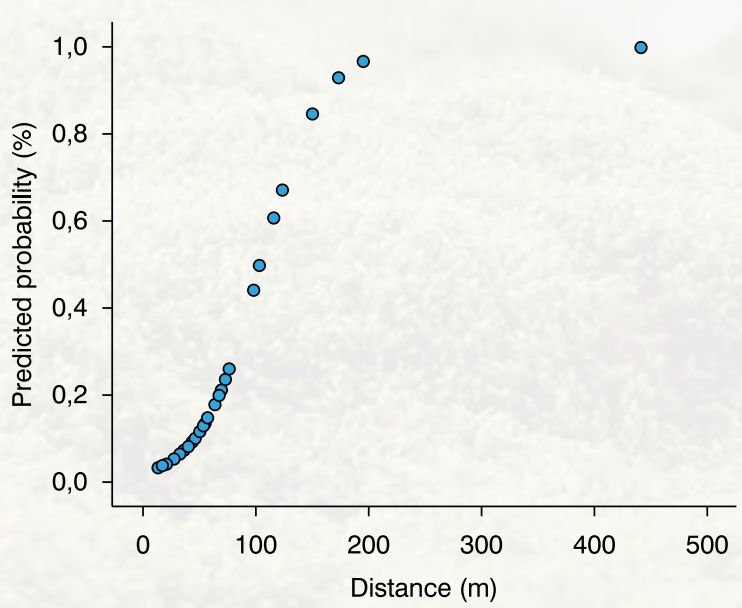

Figure 1. Distance to near neighbour - Catharacta lonnbergi chick survival predicted probability in relation to the mean distance of three nearest conspecific neighbours, Elephant Island, Antarctica.

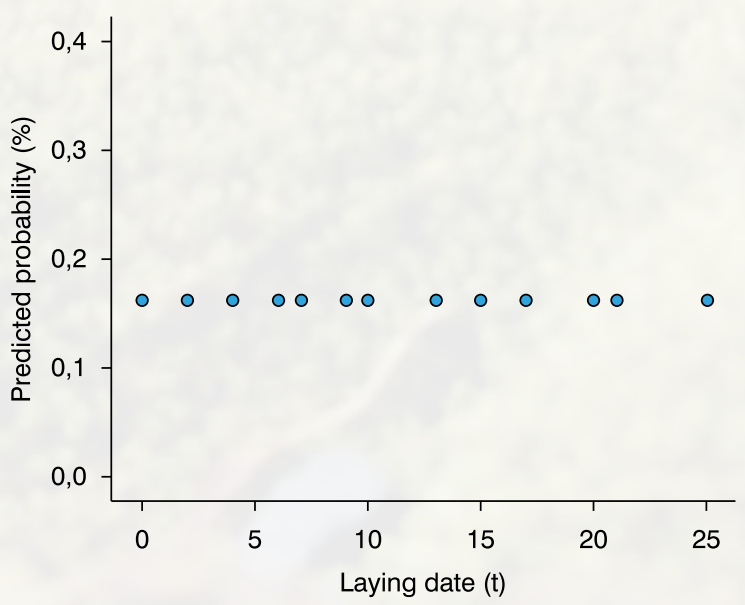

Figure 2. Egg laying date - Catharacta lonnbergi chick survival predicted probability in relation to egg laying date, where date 0 is time (t) of first egg recording, Elephant Island, Antarctica. 


\section{Discussion}

One of the causes of breeding failure in Brown Skua populations is conspecific predation (Osborn, 1985), what can be higher within closer nests. The mean distance from one nest to three nearest neighbours informs how dense or spread is the nest distribution around each studied breeding pair, so that, the greater the nest density, the greater chicks chances of conspecific predation, which may be one of the causes of higher chick death among closer nests (Figure 1). Skuas are known to be a territorial species, hence establishing and maintaining a territory usually includes costs for the owners in terms of defence efforts, such as being alert to detect and expel intruders (Hahn \& Bauer, 2008). Furthermore this behaviour results in energy wasting and consequently fitness loss. Individuals whose nests are far away from others will not have to waste so much energy on holding territory as individuals that have closer nests. In this way, adults that have distant nests are supposed to spend more energy on feeding than protecting chicks. On the other hand, closer nests were also those located closer to a penguin colony, a fact that could add some benefits to parents and chicks. Pezzo et al. (2001) also found a higher nest aggregation around penguin colonies, and states that the key factor for successful breeding in their study seemed to be the proximity to penguins, since mean fledging success was higher in nests located less than $15 \mathrm{~m}$ from penguins. According to Young and Millar (1999), the opportunity to gain food quickly (having a territory near a penguin colony) has important implications for skua breeding, it benefits the chicks in two ways: first, through higher nest attendance, they should be better protected against other skuas; and second, chicks are less likely to suffer intense hunger than those with parents foraging at sea or among few penguins - affecting survival directly or through stimulating sibling aggression.

Despite these arguments, analysis showed an opposite tendency whereby nests near the penguins showed lower probabilities of fledging chicks successfully. This may happen because, nests close to penguins are densely distributed, which increases the potential competition among breeding skuas and potentially increases intraspecific predation. Many studies show a high relation of chick condition, or probability to survive, to egg laying date and chick hatching (Pezzo et al., 2001; Hahn \& Peter, 2003; Ritz et al., 2005; Phillips et al., 1998). Egg laying date and hatching is often an index for adult quality (including age, experience, structural size and condition) rather than a date hatching factor influencing chick growth (Ritz et al., 2005). The egg laying date analysis was not significant (Figure 2), but it does not reveal inexperienced adult population because there are many other facts involved, such as climate. There is evidence that worsening environmental factors within a season are responsible for a decreasing chick growth performance and survival. Severe weather occurred during the beginning of the studied breeding season and many nests were covered with snow, which in itself caused the loss of many eggs or later as a consequence of snow melting. The loss of eggs is revealed through the very low number of fledged chicks ( 0.24 chick fledged per breeding pair), which is much below the figures recorded in studies (Phillips et al., 2004; Pezzo et al., 2001), but has already been registered in a similar way in the study of Ensor (1979). This significant chicks loss can affect Elephant Island Brown Skua population some years from now. If in the next few seasons the number of young skuas does not increase, the population could reach a limit of individuals below recoverable.

\section{Conclusion}

Analysis showed different tendencies from those presented in other studies. Chick survival probability was lower in nests near a penguin colony and an early egg laying date did not reflect a higher chick survival probability as expected. Although those tendencies can be explained, there is a huge need for more field data to monitor population trends in the coming years.

\section{Acknowledgements}

We are very grateful to National Science and Technology Institute- Antarctic of Environmental Research (INCTAPA) (CNPq Process no. 574018/2008-5, FAPERJ E-26/170.023/2008) who financially supported the project, to the Brazilian Ministry of Environment, the Ministry of Science and Technology, the Secretariat for the Marine Resources Interministerial Committee (SECIRM) and all friends who helped with field work. 


\section{References}

Ensor, P.H. (1979). The effect of storms on the breeding success of South Polar Skuas at Cape Bird, Antarctica. Notornis 26: 349-52

Hagelin, J.C. \& Miller, G.D. (1997). Nest site selection in south polar skuas: balancing nest safety and access to resources. Auk 114: 638-45.

Hahn, S. \& Bauer, S. (2008). Dominance in feeding territories relates to foraging success and offspring growth in brown skuas Catharacta antarctica lonnbergi. Behavior Ecology Sociobiology 62: 1149-57.

Hahn, S. \& Peter, H-U. (2003). Feeding territoriality and the reproductive consequences in brown skuas Catharacta antarctica lonnbergi. Polar Biology 26(8): 552-9.

Osborn, B. C. (1985). Aspects of the breeding biology and feeding behavior of the Brown Skua Catharacta lonnbergi on Bird Island, South Georgia. British Antarctic Survey Bulletin. 66: 57-71.

Pezzo, F.; Olmastroni, S.; Crosolini, S. \& Focardi, S. (2001). Factors affecting the breeding success of south polar skua Catharacta maccormicki at Edmonson Point, Victoria Land, Antarctica. Polar Biology 24: 389-93.

Phillips, R.A.; Furness, E.W. \& Stewart, F.M. (1998). The influence of territory on the vulnerability of Arctic skuas Stercorarius parasiticus to predation. Biological Conservation 86: 21-31.

Phillips, R.A.; Phalan, B. \& Forster, I.P. (2004). Diet and long-term changes in population size and productivity of brown skuas Catharacta antarctica lonnbergi at Bird Island, South Georgia. Polar Biology 27(9): 555-61.

Ritz, M. S.; Hahn, S. \& Peter, H-U. (2005). Factors affecting chick growth in the South Polar Skua (Catharacta maccormicki): food supply, weather and hatching date. Polar Biology 29(1): 53-60.

Watson, G.E. (1975). Skuas and Jaegers: Stercorariidae. In: Birds of the Antarctic and Sub-Anterctic. Richmond: The William Byrd Press Inc.

Young, E.C. \& Millar, C.D. (1999).Skua (Catharacta sp.) foraging behavior at the Cape Crozier Adelie Penguin (Pygoscelisadeliae) colony, Ross Island, Antarctica, and implications for breeding. Notornis 46:287-97. 